\title{
A PRODUCTION-INVENTORY MODEL FOR PERISHABLE ITEMS WITH DEMAND DEPENDENT PRODUCTION RATE, AND A VARIABLE HOLDING COST
}

\author{
Ruma Roy Chowdhury
}

\begin{abstract}
Basic Science and Humanities Department, University of Engineering and Management,Kolkata, West Bengal-700160, India. Email: ruma_roych@yahoo.co.in. Contact No.: +91-9748147965.
\end{abstract}

\begin{abstract}
This production-inventory model investigates the optimal time at which a production cycle should be stopped and then resumed, so that shortages in a market can be avoided. This study considers a perishable item that decays at a constant rate. The demand rate is a linear function of time. The production rate is taken to be a linear function of demand, so as to cope up with the market demand. The holding cost is taken to be a linear function of time. This mathematical model handles variable production, variable demand and variable holding cost simultaneously.
\end{abstract}

Keywords : Demand dependent production rate, linear demand, time dependent holding cost, constant deterioration.

\section{Introduction}

In the study of a dynamic market system, there are many parameters that influence the market. In the present model, a variable demand, a variable holding cost and a variable rate of production has been dealt with simultaneously. A literature review related to all the considered scenario is done. The following articles are referred to.

The ups and downs in a market is mainly dependent on the demand for a certain item. Demand of an item can be governed by various parameters like time, season, advertisement, trends, etc. In this study, a time dependent demand has been considered. These kinds of demands are common among items which are new launch in the market. With passage of time, the popularity of these items increase among the customers,hence, their market demand also increase. Tripathi [1] designed an EOQ model with time dependent demand rate and time dependent holding cost function. Rajan et al.[2] devised an EOQ model with time dependent demand, exponentially increasing holding cost and permissible delay in payments.

The rate of production plays an important role in a production inventory system. A fixed production rate has a negative impact on the goodwill of a manufacturing unit as this leads to shortage of an item in the market. Considering few of the recent studies, Mahata [3] designed a production-inventory model with backorder and lot for lot policy in fuzzy sense. Singh et al.[4] modeled a production-inventory model with partial backlogging, demand dependent production and non-instantaneous deterioration. Dey et al. [5] developed a two-echelon supply chain model where rate of production is considered variable along with a variable production cost.The model also considers Setup Time, Cost Reduction and Quality Improvement.

But in none of the above studies a variable holding cost had been considered. With production rate dependent on market demand, the holding cost cannot be taken to be constant. Holding cost should be a function of either quantity of items or on the time period for which the items are kept in storage, or the cost of refrigeration/ preservation techniques,etc. This model considers the holding cost to be dependent on time.

Reducing storage costs by avoiding unnecessarily large inventories can enhance any firms competitiveness.But at the same time, if a low inventory level is maintained, then the whole stock may sell out and the productioninventory system might face a backlog. On the other hand, if the inventory level is high, then disposing off the unsold items is required. Thus, managers of the organizations have to make a strategic decision on the amount of stock to be kept in inventory. Parmar and Gothi [6] have developed a model with time dependent holding cost for deteriorating item under quadratic demand and shortages. They had considered deterioration to follow three parameter Weibull distribution. Alfares and Ghaithan [7] modeled an inventory and pricing system with timevarying holding cost, and quantity discounts, also taking into account price dependent demand. Mishra et al. [8] established an inventory model for deteriorating items with time-varying holding cost considering time-dependent 
demand and Partial Backlogging.Yadav and Swami [9] devised an inventory model considering non-instantaneous deteriorating items with variable holding cost under two-storage.

Deterioration of a product is unavoidable and cannot be neglected while formulating an inventory model. But definitely the rate of deterioration depends on the kind of item taken into consideration.Karthikeyan et al.[10] devised an inventory model for constantly deteriorating items with cubic demand.

The objective of this paper is to develop a mathematical model and find an optimum solution procedure for a constantly deteriorating item with an exponentially varying demand, a demand dependent production rate and time dependent linear holding cost functions. A varying production rate, varying demand rate and a varying holding cost has been dealt with simultaneously. To render a more realistic approach, shortage in the system has been considered and it is completely backlogged. The model has been illustrated with the help of a numerical. A sensitivity analysis has been carried out for the optimal solution with respect to the change in the main parameters of the system which has been illustrated in tabular form as well as graphically. A real case study has been done so as to provide with a better understanding of the model to the industries.

\section{Assumptions, Notation and Decision Variables:}

\subsection{Assumptions:}

1 The model is developed for a single item.

2 Demand for the item is a linear function of time, that is, $D(t)=(\alpha+\beta t)$.

3 The production rate is linearly dependent on demand, that is, $P(t)=\gamma D(t)$. An adjustable production rate (Jauhari et al. [35])controls the market demand efficiently and avoids shortage in the market.

4 The lead time is zero.

5 In a production system with a variable production rate it is essential to maintain an optimum inventory level. When the holding cost is time dependent, a controlled production rate is very effective(see Sarkar et al. [32]). In basic inventory models, holding cost is taken constant. But in reality, holding costs depend on the time duration for which the products are stored and on the number of items stored. This model is based on a time dependent holding cost. Hence, the holding cost per unit per unit time is linearly dependent on time, that is, $C_{h}=h+r t(h, r>0)$.

6 The setup cost for the production-inventory model is constant.

7 The inventory is subjected to a constant deterioration rate, $\theta$.

8 The inventory model is developed over a finite time horizon, T.

9 The deteriorated items are neither repaired nor replaced during the time period, T.

\subsection{Notation:}

\section{Parameters:}

$I_{1}$ : Inventory level in the time period $\left[0, t_{1}\right]$ (units);

$I_{2}$ : Inventory level in the time period $\left[t_{1}, T\right]$ (units);

$P(t)$ : Rate of production (units/unit time);

$Q_{1}(t)$ : Maximum on-hand inventory possible at time $t \geq 0$ (units);

$D(t)$ : Demand at the time $t \geq 0$ (units);

$C_{h}$ : Time dependent inventory holding cost per unit item per unit time (\$/unit/unit time); 
$C_{p}$ : unit production cost per unit time (\$/unit/unit time);

$C_{d}$ : Cost of deterioration per unit item per unit time (\$/unit/unit time);

$A$ : The Setup cost per cycle (\$/cycle);

$P C$ : Total production cost in one production cycle (\$/cycle);

$D C$ : Total deterioration cost per cycle $(\$ /$ cycle $)$;

$I H C$ : Total Inventory Holding Cost in the time period $\left[0, t_{2}\right]$ (\$/cycle);

$\theta:$ Constant deterioration rate (units/unit time);

$T$ : Length of inventory cycle (years);

$h, r, \alpha, \beta, \eta, \gamma:$ Scaling and Shape parameters;

$A T C$ : The average total cost per unit time of the inventory system (\$/unit time);

\section{Decision Variables:}

$t_{1}$ : Time at which the production stops (days);

$T$ : Time at which the inventory level reaches zero in an unproductive state (days);

\section{Optimum Values:}

$t_{1}^{*}$ : Optimal time at which the production stops (days);

$T^{*}$ : Optimal time at which the inventory level reaches zero in an unproductive state (days);

$P^{*}$ : Optimal production(days);

$I H C^{*}$ : Optimal Inventory Holding Cost (days);

\section{Formulation and solution of the model}

In this section, a mathematical model of the problem is developed. The model involves a production inventory system for an item which is decaying at a constant rate. The cycle starts with a zero initial stock. The production cycle starts at $t=0$ and is demand dependent. During the interval $0 \leq t \leq t_{1}$, the items are produced at the rate of $P(t)=\gamma D(t)$. Clearly, production is a linear function of demand whereas the demand is met at the rate of $D(t)=(\alpha+\beta t)$ which is in turn linear function of time. In the time interval, $0 \leq t \leq t_{1}$, the rate at which the inventory builds up is governed by three parameters - the rate of production, the demand rate and the constant rate of deterioration. At $t=t_{1}$, the inventory reaches its highest permitted limit $Q_{1}$ and then the production is stopped. In the time interval $t_{1} \leq t \leq T$,gradual reduction in the inventory level takes place due to quenching demand and a constant deterioration of the items. At $t=T$, the inventory reduces to zero level again. After the time period $\mathrm{T}$, the production restarts and the entire cycle is repeated.

The differential equations formulating the above production inventory model are given as follows:

$$
\begin{aligned}
\frac{d I_{1}(t)}{d t}+\theta I_{1}(t) & =P(t)-D(t) & \\
& =(\gamma-1)(\alpha+\beta t), & \left(0 \leq t \leq t_{1}\right)
\end{aligned}
$$




$$
\begin{aligned}
\frac{d I_{2}(t)}{d t}+\theta I_{2}(t) & =\quad-D(t) & \\
& =\quad-(\alpha+\beta t), & \left(t_{1} \leq t \leq T\right)
\end{aligned}
$$

The boundary conditions being: $I_{1}(0)=0, I_{2}\left(t_{1}\right)=Q_{1}=I_{1}\left(t_{1}\right), I_{2}(T)=0$

The solutions for the above equations are as follows:

$$
\begin{aligned}
& I_{1}(t)=\frac{(\gamma-1)(\alpha \theta+\beta(\theta t-1))}{\theta^{2}}-e^{-\theta t} \frac{(\gamma-1)(\alpha \theta-\beta)}{\theta^{2}} \\
& I_{2}(t)=-\frac{(\alpha \theta+\beta(\theta t-1))}{\theta^{2}}+e^{\theta(T-t)} \frac{(\alpha \theta+\beta(\theta T-1))}{\theta^{2}}
\end{aligned}
$$

Substituting $I_{2}\left(t_{1}\right)=Q_{1}$ in equation (6), we get

$$
Q_{1}=-\frac{\left(\alpha \theta+\beta\left(\theta t_{1}-1\right)\right)}{\theta^{2}}+e^{\theta t_{1}} e^{\theta T} \frac{(\alpha \theta+\beta(\theta T-1))}{\theta^{2}}
$$

The total cost comprises of:

1) Setup $\operatorname{Cost}(\mathrm{OC})=\mathrm{A}$

2) The Production Cost $(\mathrm{PC})$ in the time period $\left[0, t_{1}\right]$ and $\left[t_{3}, T\right]$

$$
P C=C_{p} \int_{0}^{t_{1}} \gamma(\alpha+\beta t) d t
$$

3) The Inventory Holding Cost(IHC) in the time period $\left[0, t_{2}\right]$

$$
\begin{aligned}
I H C & =\int_{0}^{t_{1}}(h+r t) I_{1}(t) d t+\int_{t_{1}}^{t_{2}}(h+r t) I_{2}(t) d t \\
& =\int_{0}^{t_{1}}\left((h+r t)\left(\frac{(\gamma-1)(\alpha \theta+\beta(\theta t-1))}{\theta^{2}}-e^{-\theta t} \frac{(\gamma-1)(\alpha \theta-\beta)}{\theta^{2}}\right) d t\right. \\
& +\int_{t_{1}}^{T}(h+r t)\left(-\frac{(\alpha \theta+\beta(\theta t-1))}{\theta^{2}}+e^{\theta(T-t)} \frac{(\alpha \theta+\beta(\theta T-1))}{\theta^{2}}\right) d t
\end{aligned}
$$

4) The Deterioration Cost(DC) in the time period $\left[0, t_{2}\right]$

$$
\begin{aligned}
D C & =C_{d} \int_{0}^{t_{1}} \theta I_{1}(t) d t+C_{d} \int_{t_{1}}^{t_{2}} \theta I_{2}(t) d t \\
& =C_{d} \theta \int_{0}^{t_{1}}\left(\frac{(\gamma-1)(\alpha \theta+\beta(\theta t-1))}{\theta^{2}}-e^{-\theta t} \frac{(\gamma-1)(\alpha \theta-\beta)}{\theta^{2}}\right) d t \\
& +C_{d} \int_{t_{1}}^{t_{2}} \theta\left(-\frac{(\alpha \theta+\beta(\theta t-1))}{\theta^{2}}+e^{\theta(T-t)} \frac{(\alpha \theta+\beta(\theta T-1))}{\theta^{2}}\right) d t
\end{aligned}
$$

Thus the average total cost per unit time of the inventory system is given by 
AJAMC, Vol 2, Issue 1, 2022

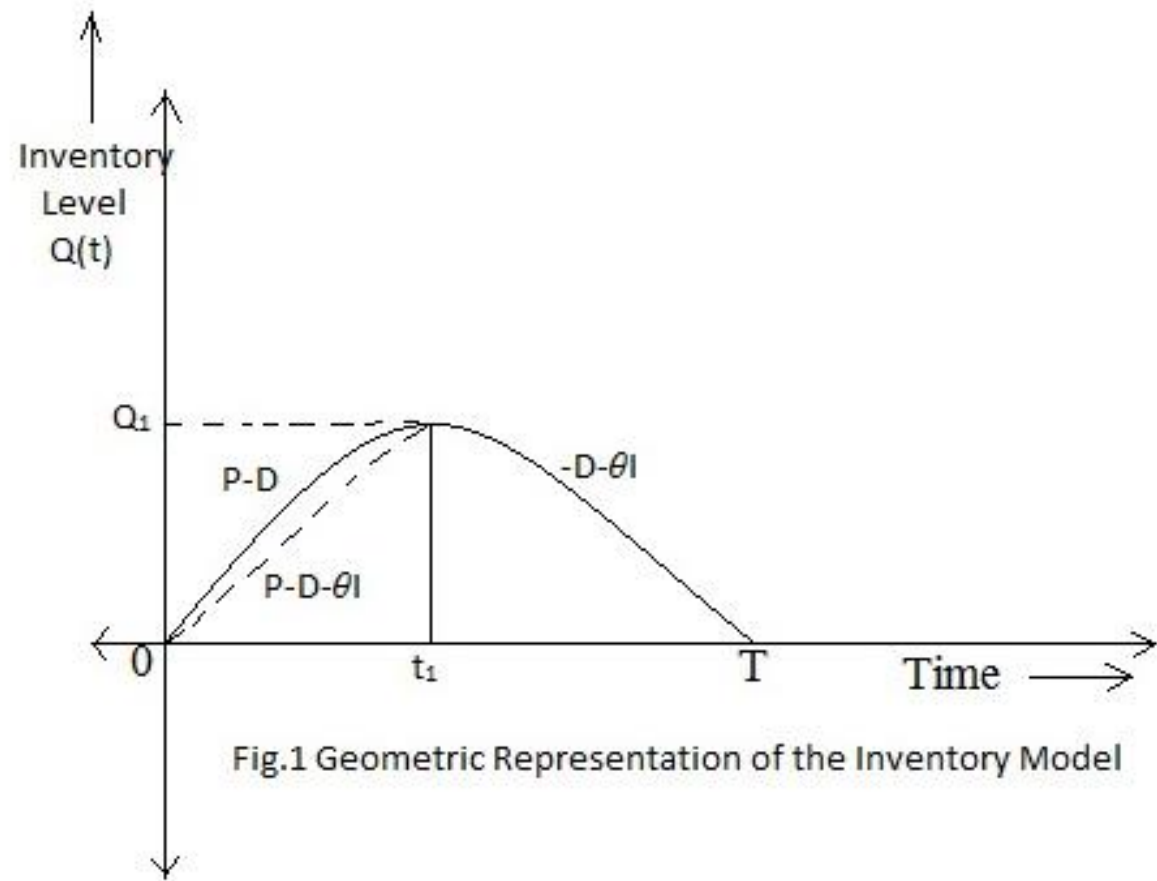




$$
\begin{aligned}
& \text { ATC }=\frac{1}{T}[\text { Setup } \\
& \qquad \begin{aligned}
A T C & =\frac{1}{T}\left[A+C_{p} t_{1} \alpha \gamma+\frac{1}{2} C_{p} t_{1}^{2} \beta \gamma+\frac{1}{\theta^{2}}(\gamma-1)\left(\frac{\alpha \theta-\beta}{\theta^{2}}\left(e^{-t_{1} \theta}\left(r+h \theta+r t_{1} \theta\right)-(r+h \theta)\right)\right.\right. \\
& \left.+\frac{1}{6} t_{1}\left(3 h\left(2 \alpha \theta+\beta\left(t_{1} \theta-2\right)\right)+r t_{1}\left(3 \alpha \theta+\beta\left(2 t_{1} \theta-3\right)\right)\right)\right) \\
& +\frac{1}{\theta^{2}}\left(\frac{(\alpha \theta+\beta(T \theta-1))}{\theta^{2}}\left(e^{\left(T-t_{1}\right) \theta}\left(r+h \theta+r t_{1} \theta\right)-(r+h \theta+r T \theta)\right)\right. \\
+\quad & \left.\frac{1}{6} T(3 h(2 \alpha \theta+\beta(T \theta-2))+r T(3 \alpha \theta+\beta(2 T \theta-3)))\right) \\
& \left.+\frac{1}{6} t_{1}\left(3 h\left(2 \alpha \theta+\beta\left(t_{1} \theta-2\right)\right)+r t_{1}\left(3 \alpha \theta+\beta\left(2 t_{1} \theta-3\right)\right)\right)\right) \\
& +\frac{C_{d}}{2 \theta^{2}}\left(-2 \alpha \theta\left(1-e^{\left(T-t_{1}\right) \theta}+T \theta-t_{1} \theta\right)+\beta\left(2+2 e^{\left(T-t_{1}\right) \theta}(T \theta-1)+\theta\left(-T^{2} \theta+t_{1}\left(t_{1} \theta-2\right)\right)\right)\right) \\
& \left.+\frac{C_{d}}{2 \theta^{2}} e^{-t_{1} \theta}(\gamma-1)\left(2 \alpha \theta-2 \beta+e^{t_{1} \theta}\left(2 \alpha \theta\left(t_{1} \theta-1\right)+\beta\left(2+t 1 \theta\left(t_{1} \theta-2\right)\right)\right)\right)\right]
\end{aligned}
\end{aligned}
$$

The objective is to minimize the average total cost function of the production inventory system to obtain the optimal scheduling strategies. The necessary conditions for minimization of $A T C\left(t_{1}, T\right)$ are

$$
\frac{\partial A T C}{\partial t_{1}}=0, \frac{\partial A T C}{\partial T}=0,
$$

$t_{1}^{*}, T^{*}$ are the solution of the above equations(12) and are the optimum values of $t_{1}, T$ respectively. All mathematical calculations in the above equations $(8,9,10,12)$ has been obtained with the help of software MATHEMATICA 9.0. These values of $t_{1}^{*}, T^{*}$ will be an optimal solution if all principal minors of the Hessian matrix(given below) are positive at $t_{1}^{*}, T^{*}$ where

$$
H=\left(\begin{array}{ll}
\frac{\partial^{2} A T C}{\partial t_{1}^{* 2}} & \frac{\partial^{2} A T C}{\partial t_{1}^{*} \partial t_{2}^{*}} \\
\frac{\partial^{2} A T C}{\partial t_{2}^{*} \partial t_{1}^{*}} & \frac{\partial^{2} A T C}{\partial t_{2}^{* 2}}
\end{array}\right)
$$

\section{NUMERICAL EXAMPLE}

The above developed production inventory model is now illustrated with a numerical example. The data of the parameters are taken randomly as follows: $A=300 \$, h=3, r=0.03, C_{d}=3 \$, \beta=0.12, \alpha=5, C_{p}=60 \$, \theta=$ $0.05, \gamma=0.5, e=2.718$.

MATHEMATICA 9.0 is used to calculate the optimal values $t_{1}^{*}, T^{*}$ from equations (12). The optimal values of $t_{1}$ and $T$ are $t_{1}^{*}=7.334$ days and $T^{*}=12.381$ days respectively and then the optimal total cost per unit time is $A T C=128.153 \$$. The optimal highest inventory level at $t_{1}^{*} a n d T^{*}$ is $Q_{1}=149.359$ unit items.

For the optimal values $t_{1}^{*}=7.334, T^{*}=12.381$ days, the Hessian Matrix is

$$
H=\left(\begin{array}{cc}
2.177 & -2.272 \\
-2.272 & 2.5538
\end{array}\right)
$$

The eigen values of this hessian matrix are real and positive for the optimal values of $t_{1}^{*}$ and $T^{*}$. The eigen values are $H_{1}=4.6452>0, H_{2}=0.0856>0$, Thus the Hessian Matrix is positive definite at the optimal values $t_{1}^{*}, T^{*}$. Hence, the Average Total Cost of the Production-Inventory system is minimum at these optimal values. 


\section{AJAMC, Vol 2, Issue 1, 2022}

\section{Managerial Insight:}

In this study, the item considered has a time dependent demand. As a result, in order to cater to the customer demand for an item, the production rate has to be in linear variation with demand. More investments have to be made in order to hold and maintain these manufactured products in inventory. The major insights of this study are as follows:

- The managers can decide upon the optimum time $t_{1}^{*}$ at which the production is to be stopped. The customer demand is served from the accumulated inventory after stopping the production. The managers have an idea about the optimal time $\mathrm{T}$, at which the inventory level will reach zero and the production should be started there of in order to prevent backlog.

- Resuming the production at the right time $T$ will keep shortages well under control and at the same time there is no harm to the goodwill of the company.

- As the managers can monitor the start and stop time of production based on this model, it helps in controlling the excess units of production which in turn helps to control the variable holding cost. This way the manufacturing unit can plan an optimum rate of production which leads to optimizing the variable holding cost simultaneously.

\section{Conclusion:}

The present paper deals with a production inventory system with deteriorating items that perish at a constant rate. The production rate is a linear function of demand, which in turn varies proportionally with time. An assumption of a variable holding cost - a linear function of time, is done in order to give the model a more realistic approach.

This model gives the optimum time at which the production is stopped. The maximum inventory that is allowed to accumulate is calculated. The production stops only when this inventory level builds up. The inventory level building depends on three factors- production rate, demand rate and constant deterioration rate. The demand is fulfilled with this accumulated inventory. Once the inventory level reaches zero mark, the production resumes. The optimum time at which the production resumes is also calculated by this model. This controlled production helps in maintaining the market balance by satisfying demand and also helps in avoiding shortages. Also, the optimum rate of production (stopping and resuming production as and when required) helps in incurring fewer financial amounts to the variable holding cost. Optimizing the time of stopping and starting the production cycle helps to minimize the average total cost of the production-inventory system.

The major contribution of this work is to guide the managers of the manufacturing units to be in a better position to take decision regarding a controlled rate of production, thus avoiding shortages, without losing the goodwill of the company, manage an optimized variable holding cost.

\section{Future Extension:}

In future, this model can be extended by considering an imperfect production system. A weibull distribution deterioration rate may be considered. Also,implementation of autonomation strategies to identify the imperfect items during the production run,and control the work process, will give a new direction towards the establishment of a smart production system. This model can also be extended by considering a lead time uncertainty.

This research did not receive any specific grant from the funding agencies in the public, commercial or not-for-profit sectors.

\section{References}

1. Tripathi,R.P., (2011),'EOQ Model with Time Dependent Demand Rate and Time Dependent Holding Cost Function', International Journal of Operations Research and Information Systems, Vol. 2(3), pp.79-92. DOI: 10.4018/joris.2011070106 
2. Sundara Rajan, R., Uthayakumar, R.,(2017), 'EOQ Model for Time Dependent Demand and Exponentially Increasing Holding Cost Under Permissible Delay in Payment with Complete Backlogging', International Journal of Applied and Computational Mathematics, Vol. 3,pp. 471487. https://doi.org/10.1007/s40819-015-0110-2

3. Mahata,M.C.,(2015), 'An integrated production-inventory model with backorder and lot for lot policy in fuzzy sense', International Journal of Mathematics in Operational Research,Vol.7(1),pp.69-102.

4. Singh,S., Singh,S.R., Sharma,S.,(2017), 'A partially backlogged EPQ model with demand dependent production and non-instantaneous deterioration', International Journal of Operational Research, Vol. 10(20), pp.211-228.

5. Dey,B.K., Sarkar,B., Pareek,S.,(2019), 'A two-echelon supply chain management with setup time and cost reduction, quality improvement and variable production rate', Mathematics, Vol. 7(4), pp.328. https://doi.org/10.3390/math7040328

6. Parmar,K., Gothi,U.B.,(2015), 'Epq model for deteriorating items under three parameter weibull distribution and time dependent ihc with shortages', American Journal of Engineering Research,Vol.4(7),pp.246-255.

7. Alfares,H.K., Ghaithan,A.M.,(2016), 'Inventory and pricing model with price-dependent demand, time-varying holding cost, and quantity discounts', Computers \& Industrial Engineering,Vol 94, pp. 170-177.

8. Mishra V.K.,Singh L.S.,Kumar,R.,(2013), 'An Inventory Model for Deteriorating Items with Time-Dependent Demand and Time-Varying Holding Cost under Partial Backlogging', International Journal of Industrial Engineering, Vol.9(4), pp.1-5.

9. Yadav,A.S., Swami,A.,(2019), 'An inventory model for non-instantaneous deteriorating items with variable holding cost under two-storage', International Journal of Procurement Management, Vol.12(6), pp.690-710.

10. Karthikeyan,K.,Santhi,G.,(2015),'An inventory model for constant deteriorating items with cubic demand and salvage value', International Journal of Applied Engineering Research, Vol.10 No.55,pp.0973-4562. 